\title{
Lexis
}

Journal in English Lexicology

18 | 2021

Lexical learning and teaching

\section{A Frame-Inspired Task-Based Approach to Metaphor Teaching}

\section{Thomai Dalpanagioti}

\section{(2) OpenEdition \\ 1 Journals}

\section{Electronic version}

URL: https://journals.openedition.org/lexis/5839

DOI: $10.4000 /$ lexis.5839

ISSN: 1951-6215

\section{Publisher}

Université Jean Moulin - Lyon 3

\section{Electronic reference}

Thomai Dalpanagioti, "A Frame-Inspired Task-Based Approach to Metaphor Teaching", Lexis [Online], 18 | 2021, Online since 18 December 2021, connection on 21 December 2021. URL: http:// journals.openedition.org/lexis/5839; DOI: https://doi.org/10.4000/lexis.5839

This text was automatically generated on 21 December 2021.

\section{(c) (i) (9)}

Lexis is licensed under a Creative Commons Attribution-NonCommercial-NoDerivatives 4.0 International License. 


\title{
A Frame-Inspired Task-Based Approach to Metaphor Teaching
}

\author{
Thomai Dalpanagioti
}

\section{Introduction}

1 A growing body of studies have explored the relevance of cognitive linguistics (CL) to foreign language teaching/learning (for overviews, see Littlemore \& Low [2006]; Boers \& Lindstromberg [2008]; Littlemore [2009]; Littlemore \& Juchem-Grundmann [2010]; MacArthur [2016]; Low [2019]). Key CL concepts that have been found particularly relevant to the field of foreign language teaching/learning include embodied cognition, linguistic motivation, encyclopedic knowledge, cross-linguistic differences in construal and categorization, the entrenchment of metaphor and metonymy in human thought and expression, and the usage-based nature of language knowledge and learning (Littlemore [2009: 1-11]). CL-inspired approaches to the instruction and study of foreign languages exploit mimes, mental images, meaningful groupings and noticing activities, with the benefit of in-depth understanding and better memorization (Holme [2004]; Boers \& Lindstromberg [2008]; MacArthur [2016]).

2 However, as MacArthur [2016: 420] points out, "CL-inspired research has had little impact on actual language teaching" and syllabus design. As regards figurative language in particular, a major obstacle to incorporating it in instructional programmes is its marginal representation in published teaching materials (MacArthur [2016: 418]). Assessing the extent to which figurative thinking is reflected in English as a Foreign Language (EFL) textbooks, Littlemore \& Low [2006: 203-209] have identified a traditional approach (which "present[s] figurative language as something special"), a somewhat artificial "conceptual metaphor" approach (which organizes lessons along conceptual domains), and a more challenging approach, which "attempt[s] to integrate figurative language into the textbook." The challenge is ongoing, and there is currently a call for shifting the focus from the form and meaning of metaphors to their use in discourse (MacArthur [2016: 421]). 
3 It is in this respect that the present paper aims to make a contribution by exploring the way that a particular CL theory, frame semantics, can be combined with a communicative teaching methodology, the task-based approach, to design usage-based teaching materials on metaphor. Promoting an encyclopedic view of meaning, frame semantics has implications for teaching the paradigmatic and syntagmatic relationships between L2 words (Littlemore [2009: 75-93]); it can thus be relevant to an investigation of the conceptual and linguistic aspects of learning and using metaphor. Similarly, the potential of task-based learning to help learners capture the functional and phraseological aspects of figurative language has been touched upon (Littlemore \& Low [2006: 198]). Yet the integration of these two models seems not to have been examined from a theoretical or practical perspective.

4 Against this background, in section 1 we first briefly present frame semantics and its most conspicuous manifestations, FrameNet and MetaNet; we also summarize proposals for their use in the context of foreign language teaching. We then discuss the basic tenets of Willis's [1996a] task-based learning framework (section 2), and explain why it seems to be compatible with frame semantics (section 3). To demonstrate the relevance of integrating the two models, section 4 outlines two frame-inspired taskbased lesson plans, which raise EFL learners' metaphor awareness. In an attempt to show how the sample lesson plans can be incorporated into the EFL syllabus and classroom, they are linked to topics in an EFL textbook at the B2 European reference level.

\section{Frame semantics}

\subsection{The theoretical framework and applications}

5 Frame semantics is a cognitive linguistic theory that offers a usage-based perspective on meaning. The central idea of frame semantics is expressed by Fillmore [1985: 231] in the following way: "linguistically encoded categories [...] presuppose particular structured understandings of cultural institutions, beliefs about the world, shared experiences, standard or familiar ways of doing things and ways of seeing things". This encyclopedic knowledge is called a "(semantic) frame" and is inextricably linked to linguistic knowledge. ${ }^{1} \mathrm{~A}$ word - more precisely a lexical unit (i.e. a word in one of its senses) - is said to "evoke" a frame. ${ }^{2}$ Every frame consists of specific "frame elements" (FEs), i.e. the "various participants, props, and other conceptual roles" involved in the schematic representation of a situation [Fillmore \& Petruck 2003:359]. Frame semantics connects these situation-specific semantic roles to their syntactic realizations (grammatical functions and phrase types), thus explicitly linking the semantic and combinatorial features of lexical units (LUs).

6 The main application of frame semantics is the Berkeley FrameNet project, ${ }^{3}$ which has been building an online lexical resource for English, and is also used as a basis for the construction of parallel FrameNets in other languages [Boas 2017: 564-565]. Work in the FrameNet project involves developing frame descriptions (including frames, FEs and frame-to-frame relations), establishing LUs (for single words or multiword expressions) as annotation targets, extracting example sentences from the British National Corpus, and annotating them in terms of FEs, phrase types, and grammatical functions [Ruppenhofer et al. 2016: 7-8]. By way of illustration, Figure 1 provides part of the 
description of the [Self_motion] frame: the common situation of moving under one's own power is defined in terms of a number of FEs, which are colour-coded and exemplified in a corpus-derived sentence. ${ }^{4}$ The syntactic realizations of FEs are provided in separate reports. ${ }^{5}$

Figure 1. Sample screenshot from FrameNet's [Self_motion] frame description

\section{Self motion}

\section{Definition:}

The Self mover, a living being, moves under its own direction along a Path. Alternatively or in addition to Path, an Area, Direction, Source, or Goal for the movement may be mentioned. She WALKED along the road for a while.

7 The [Self_motion] frame involves a SELF_MOVER, who moves from a SOURCE to a GOAL along a PATH, and is evoked by both single-word LUs (e.g. walk, run, stagger, jump) and multi-word ones (e.g. make a beeline, take to the air). Besides these core FEs, the [Self_motion] frame report shows peripheral FEs, such as COTHEME, DISTANCE, DURATION, MANNER, SPEED, etc., and the relations between this frame and others (e.g. [Intentionally_act] and [Motion]). However, the metaphorical relation between frames is not similarly marked as a frame-to-frame relation: as Ruppenhofer et al. [2016: 101] explain, FrameNet has not "annotated both the source and target domains on the same sentence, since such work is worthy of an entire research project in itself".

The issue of systematic metaphor treatment is addressed in another, more recent, application of frame semantics, the MetaNet project. ${ }^{6}$ This project develops a metaphor computing system based on conceptual metaphor theory [Lakoff \& Johnson 1980] and frame semantics and driven by corpus data. Considering metaphors as mappings between semantic frames, MetaNet has created a structured repository of interrelated metaphors and frames that act as source and target domains. As David [2017: 580] notes, "the value of the MetaNet system lies precisely in its ability to link linguistic metaphors with deeper semantic domains and mappings". ${ }^{7}$ Presenting the MetaNet architecture, David [2017] further explains that the (conceptual, lexical, grammatical) repository is embedded in an automated metaphor identification mechanism which is used to detect metaphoric collocations in any type of text. By way of illustration, Figure 2 shows how relations among frames and metaphors, alongside illustrative examples, are provided in the publicly available MetaNet repository. The [Self_motion] and [War] source frames shown in Figure 1 and Figure 2 are used in the lesson plans presented below in this paper. 
Figure 2. Sample MetaNet entry for the metaphor DISEASE TREATMENT IS WAR

\begin{tabular}{|l|l|}
\hline Source Frame & Ware \\
\hline Target Frame & Disease treatment? \\
\hline
\end{tabular}

Mappings:

\begin{tabular}{|l|l|}
\hline diseased_cells & $<=$ enemy_combatants \\
\hline medical_professionals & $<=$ army \\
\hline doctors & $<=$ generals \\
\hline body & $<=$ battlefield \\
\hline
\end{tabular}

medical_tools_and_medicines $<=$ weapons

\begin{tabular}{|l|l|l}
\hline treatment_strategy & $<=$ war_strategy
\end{tabular}

\begin{tabular}{|l|l|l|}
\hline applying_treatment & $<=$ fighting \\
\hline
\end{tabular}

Examples:

Example Text: The doctors at the $\mathrm{CDC}$ led the way to victory against the flu epidemic.

Example Text: The cancer patient fought a long, hard, battle, but she eventually succumbed to her disease.

Example Text: A Triumph in the War Against Cancer

Provenance: http://www. smithsonianmag.com/science-nature/A-Victory-in-the-War-Against-Cancer.html 函

Example Text: With nothing left in their leukemia-fighting arsenal, the doctors were down to Dilaudid, a derivative of morphine.. Provenance: http://www.smithsonianmag.com/science-nature/A-Victory-in-the-War-Against-Cancer.html tes

\section{Graph of related metaphors:}

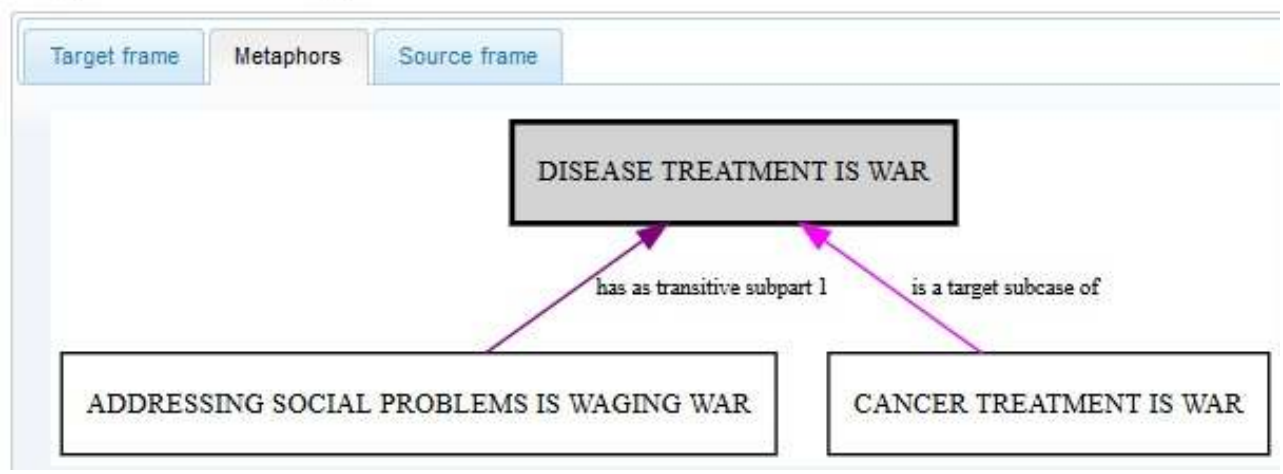

\subsection{Frame semantics in foreign language teaching}

9 Frame semantics has been applied in several research areas such as lexicology, lexicography, syntax and grammar in general (Petruck [1996]; Boas [2005]), translation 
(Czulo [2017]), and terminology (L'Homme [2020]). However, the pedagogical potential of frame semantics seems to be relatively unexplored.

Only a handful of studies have approached language teaching from a frame-semantic perspective. These studies essentially view semantic frames as a tool for facilitating vocabulary acquisition. Xu \& Li [2011], for instance, point out benefits in terms of vocabulary expansion, enhancement of long-term memory and development of pragmatic knowledge - i.e. benefits which arise from the ability of semantic frames to group words in contexts and link them to real world experiences. Similarly, Friberg Heppin \& Friberg [2012: 640] argue that FrameNets of different languages will be useful resources for communicative language teaching because frames could help teachers "introduce situations in natural sequence, while annotated sentences could show patterns of expression". However, neither Xu \& Li [2011] nor Friberg Heppin \& Friberg [2012] provide sample teaching material to give concrete examples of how to use semantic frames in language teaching.

11 Introducing vocabulary in terms of semantic frames is also proposed in Esbrí-Blasco [2014] and a set of activities are provided to illustrate potential benefits in terms of comprehension and retention. In particular, focusing on the domain of cooking, the proposed activities ask students to relate their background experience to frames, categorize specific lexical items in terms of frames and discuss the meaning of metaphorical expressions. In the context of learning German as a foreign language, Boas \& Dux [2013] describe a frame-based pedagogical resource which draws on English FrameNet entries and their German counterparts as well as corpus examples in order to highlight syntactic, semantic and pragmatic differences between English and German LUs evoking the same semantic frame. Boas \& Dux [2013] report positive preliminary findings on its effectiveness, which is attributed to raising learners' awareness of crosslinguistic differences in meaning and grammar.

Lastly, Jódar-Sánchez [2019] seems to offer the most extensive discussion of the pedagogical application of FS by describing a number of ways in which the Spanish FrameNet can be used to teach vocabulary, grammar and metaphors to learners of Spanish as a foreign language. As regards the teaching of metaphors in particular, Jódar-Sánchez [2019: 140-142] outlines some preliminary ideas on how FrameNet and MetaNet could be used in activities that ask learners to identify metaphors in texts or example sentences and to discover FE mappings between source and target frames.

What is obviously missing from the existing literature is a comprehensive methodological framework for applying frame semantics to language teaching. To narrow the gap between CL theory and foreign language teaching practice, this paper proposes integrating frame-semantic theory with task-based learning methodology. The next sections attempt to show how a CL framework not primarily designed for foreign language teaching can be used for that purpose if buttressed with a framework designed for that.

\section{Task-based language teaching}

14 Over the last three decades, task-based language teaching (TBLT) has gathered considerable momentum in Europe and elsewhere. Various researchers have proposed communicative tasks as a central unit of planning and teaching: as Rod Ellis and his colleagues [2020:23] point out, "TBLT is not monolithic but incorporates a range of 
possibilities which share the central idea that a language is best learned through the effort to use it communicatively". Emphasizing the dynamic process of learning and the role of context and social interaction, TBLT takes a usage-based perspective on learning. As Ellis [2017:111] explains, in usage-based theories language learning is viewed as proceeding gradually from learning ready-made chunks to deconstructing and reconstructing them; that's why in TBLT "there is no attempt to teach learners declarative knowledge of target features prior to the performance of a task" (Ellis [2017: 111]).

This methodology uses explicit instruction the least; it prioritizes learners' engagement, focus on meaning, completion of an outcome, and resemblance to realworld activities (Willis \& Willis [2007: 13]). The question of whether or not an explicit focus on form has a place in this context has caused great controversy. Nunan [2004: 21-22] summarizes the strong and weak interpretations of TBLT, which consider focus on form unnecessary and necessary respectively, and supports the latter by arguing for "a pedagogy that reveals to learners systematic interrelationships between form, meaning and use". Reviewing four different versions of TBLT, Ellis [2017: 112-113] points out that all these approaches acknowledge the necessity of form-focused elements, but they differ as regards the phase (pre-task, main task, post-task or all phases) in which they should be incorporated. ${ }^{8}$

For example, a TBLT framework which combines focus on meaning with focus on form has been proposed by Willis [1996a], [1996b]. In this framework, a "task" is defined as "a goal-oriented activity in which learners use language to achieve a real outcome" and a lesson is structured in three phases, i.e. pre-task, task cycle, and language focus (Willis [1996a: 38], [1996b: 53]). More precisely, the pre-task phase introduces learners to the topic and prepares them for the main task; the task cycle is organized in three stages: task (learners do the task in small groups), planning (learners prepare to report on the task to the whole class), and report (each group presents its report to the whole class); lastly, the language focus phase has two components: analysis (consciousnessraising activities) and practice on the language forms noticed in the analysis stage (Willis [1996a], [1996b]). This framework does not eschew a focus on form, nor does it allow "form-focused activities to detract from a focus on meaning" by carefully placing them after the task cycle (Willis \& Willis [2007: 113]). Willis's TBLT framework is a flexible, learner-centred model which approaches language holistically, proceeds from free language use in purposeful interaction to awareness-raising language analysis, combines incidental/implicit and intentional/explicit L2 learning, ${ }^{9}$ promotes both fluency and accuracy, and integrates all four skills (listening, speaking, reading, writing).

Willis's TBLT framework seems promising for the teaching of metaphor. It is along the lines of this three-stage framework that Littlemore \& Low [2006: 201] sketch a lesson which aims to encourage figurative language production. In this example, the preparation of an ice-cream advertisement in small groups is the goal of the task cycle, during which learners are likely to produce creative figurative language; an advertisement for other food products which employs metaphor can be used in the pretask, while during the language focus phase learners' attention can deliberately be drawn to conventional and novel figurative language use. This example hints at the potential of TBLT for teaching the different aspects of metaphor (e.g. conceptual, lexico-grammatical, textual, communicative) by incorporating explicit awareness- 
raising activities into implicit-learning situations. This line of argument is extended here by bringing frame semantics into the picture.

\section{Integrating frame semantics with task-based language teaching} knowledge and language learning. As Dolgova \& Tyler [2019] observe, what usage-based approaches to language and language learning share is "a focus on how contextualized language is used to make meaning" [2019:940] and "their emphasis on the notion that actual language use is a primary shaper of linguistic form and the foundation for language learning" [2019:941]. Sections 1 and 2 have pointed out that meaningful, contextualized language use lies at the core of both frame semantics and TBLT; most importantly, both models refer to both situational and linguistic context. On the one hand, the concept of semantic frame captures situational context and, by linking FEs to their linguistic realizations, frame semantics takes account of linguistic context as well. On the other hand, TBLT is also based on communicative situations. It involves learners in using language naturally in order to achieve a communicative outcome (task cycle); yet, it also allows for focus on linguistic context mainly in the last stage (language focus), when learners' attention is drawn to accurate use of linguistic forms previously encountered incidentally.

To further demonstrate the compatibility of the two models, Table 1 recasts Willis's TBLT model in frame-semantic terms. Frame semantics is employed in a different way in each one of the three stages of the TBLT framework. Two comments are necessary here. First, the pedagogical application of frame-semantic theory is dependent on the resources which have been developed from this theory (FrameNet and MetaNet). These lexicographic tools provide interconnected inventories and entries for frames, lexical units, metaphors, etc., and are therefore well-suited for awareness-raising activities. Secondly, the use of frame-semantic tools can be direct or indirect. It is direct when learners, like researchers, engage in their own linguistic analysis in which they focus on specific linguistic features (language focus phase), and indirect during the first two phases, which draw learners' attention to a communicative goal.

Table 1. Integrating frame semantics and task-based language teaching

\begin{tabular}{|l|l|}
\hline TBLT & Frame semantics \\
\hline Pre-task & Identification of frame(s) \\
\hline Task cycle & Active involvement in the frame(s) (fluency) \\
\hline Language focus & Linking FEs to lexico-grammatical items (accuracy) \\
\hline
\end{tabular}


In its indirect application, we can use frame semantics to inform the design of the tasks: in the pre-task the identification of a frame (or frames) can help learners situationally contextualize the main task (and hence the lesson), while in the task cycle they are actively involved in L2 production in the identified frame(s), incidentally acquiring the linguistic realizations of FEs. For example, if the main task involves students in describing a journey (they have recently made, or they remember well, or that did not go as planned, etc.), the pre-task can provide the general context by familiarizing students with the [Motion] frame; the linguistic realizations of core FEs, such as THEME, SOURCE, GOAL, PATH, and non-core FEs, such as DEPICTIVE, PATH_SHAPE, MANNER, SPEED, TIME, will naturally come up in the task cycle. When planning a TBLT lesson with semantic frames in mind (e.g. the general [Motion] frame or its sub-frames like [Self-motion], [Fluidic_motion], [Mass_motion], etc.), we can add coherence to the free learning process and may even predict the language that will occur in classroom (e.g. manner-of-motion verbs, satellites, prepositional phrases, etc.). In this way, teachers may overcome some of the problems they face with TBLT, such as fear of losing control of the language the learners are using, and other issues related to managing groupwork and the class in general (Willis \& Willis [2007: 200]). As the lesson moves from the task cycle (incidental/implicit learning) to the language focus phase (intentional/explicit learning), we similarly shift from indirect to direct use of frame semantics. In the last stage, frame-aided language focus can take different forms and range from controlled activities to more autonomous consultation of frame-semantic resources (discovery learning); ${ }^{10}$ in any case, learners get the opportunity to notice and practise lexico-grammatical items evoking the frame(s) they first actively engaged in.

On the whole, as a result of increased contextualization (situational and linguistic), this integrated model provides opportunities for highlighting conceptual and phraseological patterns. By way of illustration, the next section outlines the design of two sample lesson plans.

\section{Application: designing sample teaching materials}

This section reports two examples of how we can apply the frame-inspired task-based teaching approach outlined above to the design of teaching materials that can be used to raise learners' awareness of metaphor. Metaphor is a conceptual, linguistic and discursive phenomenon, and as such it allows us to see the contextualization possibilities offered by the proposed integrated approach, which keeps metaphor contextualized and draws learners' attention to both situational context and linguistic co-text. The two teaching units provided in the Appendix are designed for learners of English as a foreign language at the B2 reference level for communicative competence. Depending on the number of students, these units may stretch over three or four teaching hours.

In designing the teaching units, we have taken account of the Framework-related descriptor scale proposed by Littlemore et al. [2014: 142] for metaphor use; at B2 level in particular, it is specified that:

learners should be able to make use of a limited number of conventional and creative open-class metaphors. They should be able to use metaphors for evaluative and discourse organizing purposes. They should be starting to use personification 
metaphors more extensively. Metaphorical clusters are more in evidence at this level. Some are coherent, whereas others contain mixed metaphors.

Littlemore and her colleagues emphasize the significance of incorporating focus on metaphor in the syllabus at this level, as this is where learners start to use metaphor in new ways, often relying on L1: teaching metaphor at this level aims "not only to introduce learners to conventionalized metaphors, but also to encourage them to use metaphors creatively to express themselves" [2014: 143]. ${ }^{11}$ Nevertheless, as MacArthur [2016: 418] observes, metaphor has a marginal position in EFL teaching materials, and it can be found more often in dictionaries or specialized activity books than in coursebooks normally used in classroom. Taking this gap into account, we propose teaching material that is thematically linked to specific units in the Gateway B2 coursebook [Spencer 2016], and potentially to similar units of any B2 level EFL coursebook. More precisely, the proposed lessons might serve as a follow up to units on life stories and health problems.

Following the TBLT framework both lessons are organized in three stages, and framesemantic input is provided as shown in Table 1. In both cases, the pre-task speaking activity introduces learners to the topic of each lesson by guiding them to activate two frames (i.e. LIFE and JOURNEY in the first lesson, DISEASE and WAR in the second one). As a warming up session - prompted by a famous quotation in the first lesson, and by a video in the second one - the pre-task in both cases sets the situational context and aims to stimulate the learners' interest for the main task ahead.

During the task cycle learners are actively involved in the target frame (i.e. life experiences in the first lesson, a deadly disease in the second one) through exposure to and use of the target language in a real communicative situation, combining factfinding and decision-making. Emphasis is on building fluency and raising motivation within the privacy of small groups. The use of MOTION (source frame) to refer to LIFE EXPERIENCES (target frame) in the first lesson and the use of WAR (source frame) to refer to DISEASE TREATMENT (target frame) in the second one is encountered incidentally (i.e. featured in the support material without further explanation).

8 In the third and final stage (language focus), the learners' attention shifts to intentional noticing of metaphorical language use and accuracy. In both lessons, learners first explore source-target frame mappings and lexico-grammatical realizations of FEs heuristically. They then get further practice through awareness-raising activities that range from controlled gap-filling to guided writing to free speaking. The sample activities demonstrate how FrameNet (in the first lesson) and MetaNet (in the second lesson) can be incorporated in the analysis and practice stages; the data used have been carefully selected so that the technicalities of these resources do not place great demands on teachers or learners.

At the end of these lesson phases, it would be interesting to have learners reflect on their productions in the task cycle, in light of the language forms they focused on in the last stage of the lesson. In an additional phase, they could try to inject metaphor into their texts to make them more vivid. It is also important to involve learners in the evaluation of the lesson. The teacher could ask learners about their experience in group work and their feelings, what they found too difficult or too easy, useful or irrelevant to their needs, etc. The reflective questions could be discussed in class (in L2) in order to prompt meaning-focused language use and involve learners in subsequent lesson planning, thus enhancing their motivation (Willis \& Willis [2007: 40]). ${ }^{12}$ 
the whole, the sample frame-inspired TBLT teaching units in the Appendix showcase the features of a well-balanced course: combining meaning-focused input, language-focused learning, meaning-focused output and fluency development (Nation [2013:591]). The integration of frame semantics into TBLT not only increases contextualization but also promotes discovery learning at all stages of the lesson.

\section{Conclusion}

This paper explores the common usage-based ground between a cognitive linguistic theory (frame semantics) and a language teaching method (task-based learning). Our overall objective has been to theoretically support and practically apply the idea of jointly using frame semantics and TBLT in designing L2 teaching materials. Taking account of Drożdż \& Taraszka-Drożdż's [2020: vii] recent call for "translating theoretical positions [...] into classroom practice", we offer sample frame-inspired taskbased teaching units that can be readily used in the EFL classroom to enhance learners' metaphor awareness. Highlighting the key role of contextualization (both situational and linguistic), our approach might help learners discover, organize, practice, and hence memorize vocabulary as patterns in a situational and phraseological context. The teaching materials presented here represent an initial exploration of the synergy between frame semantics and TBLT, paving the way for research that could look at its effectiveness, and learner reactions to explicit work on metaphor.

The proposed lesson plans may give teachers or coursebook writers ideas for incorporating tools like FrameNet and MetaNet into their classroom materials. Users need to be aware that frame-semantic applications are technologically demanding, and require time and resources to be integrated into classroom practice. They should be focused and organized, so that learners are not overwhelmed by technicalities or too much information at once.

The focus of this paper has been on "task-as-workplan", i.e. the task teaching materials, which can then be applied in practice and explored as "task-as-process" (Ellis [2017: 108]). Therefore, once lesson plans and teaching materials are created along the lines set out in this paper, the validity and effectiveness of the integrated approach can be tested through small- and large-scale empirical studies. Evidence from applications in classroom supporting the usefulness of this approach might not only spearhead a wave of research into the application of frame-semantic resources in foreign language teaching, but it might also have an effect on the design of these resources - i.e. extensive application of frame-semantic data in foreign language teaching would raise the need for simplified, pedagogically-oriented versions of the original frame-semantic resources. 


\section{BIBLIOGRAPHY}

BOAS Hans, 2005, "From theory to practice: Frame semantics and the design of FrameNet", in LANGER Stefan \& SCHNORBUSCH Daniel (Eds.), Semantisches Wissen im Lexikon, Tübingen: Narr, 129-160.

BOAS Hans, 2017, "Computational Resources: FrameNet and Constructicon", in DANCYGIER Barbara (Ed.), The Cambridge Handbook of Cognitive Linguistics, Cambridge: Cambridge University Press, 549-573.

BOAS Hans \& DUX Ryan, 2013, "Semantic frames for foreign language education: Towards a German frame-based online dictionary", Veredas: Frame Semantics and its Technological Applications 17(1), $82-100$.

BOERS Frank \& LINDSTROMBERG Seth, 2008, Cognitive Linguistic Approaches to Teaching Vocabulary and Phraseology, Berlin \& New York: De Gruyter Mouton.

CIENKI Alan, 2007, "Frames, idealized cognitive models, and domains", in GEERAERTs Dirk \& CUYCKENS Hubert (Eds.), The Oxford Handbook of Cognitive Linguistics, Oxford: Oxford University Press, $170-187$

CZULO Oliver, 2017, "Aspects of a primacy of frame model of translation", in HANSEN-SCHIRRA Silvia, CZULO Oliver \& HOFMANN Sascha (Eds.), Empirical Modelling of Translation and Interpreting, Berlin: Language Science Press, 465-490.

DAVID Oana, 2017, “Computational approaches to metaphor: The case of MetaNet”, in DANCYGIER Barbara (Ed.), The Cambridge Handbook of Cognitive Linguistics, Cambridge: Cambridge University Press, 574-589.

DOLGOVA Natalia \& TYLER Andrea, 2019, “Applications of usage-based approaches to language teaching", in GAO Xuesong (Ed.), Second Handbook of English Language Teaching (Springer International Handbooks of Education Series), Switzerland: Springer, 939-961.

DROŻDŻ Grzegorz \& TARASZKA-DROŻDŻ Barbara, 2020, Foreign language pedagogy in the light of cognitive linguistics research, Berlin: Springer.

ELLIS Rod, 2017, “Task-Based Language Teaching”, in LOEWEN Shawn \& SATO Masatoshi (Eds.), The Routledge Handbook of Instructed Second Language Acquisition, New York \& London: Taylor \& Francis, 108-125.

ELLIS Rod, SKEHAN Peter, LI Shaofeng, SHINTANI Natsuko \& LAMBERT Craig, 2020, Task-Based Language Teaching: Theory and Practice, Cambridge: Cambridge University Press.

ESBRÍ-BLASCO Montserrat, 2014, "Applying semantic frames to effective vocabulary teaching in the EFL classroom", Fòrum De Recerca 19, 743-752.

FILLMORE Charles, 1985. "Frames and the semantics of understanding", Quaderni di Semantica 6(2), 222-254.

FILLMORE Charles \& PETRUCK Miriam, 2003, "FrameNet glossary", International Journal of Lexicography 16(3), 359-361.

FRIBERG HEPPIN Karin \& FRIBERG Hakan, 2012, “Using FrameNet in communicative language teaching”, in FJELD Ruth Vatvedt \& TORJUSEN Julie Matilde (Eds.), Proceedings of the XV EURALEX International Congress, Oslo: University of Oslo, 640-647. 
GILQUIN Gaëtanelle \& GRANGER Sylviane, 2010, "How can data-driven learning be used in language teaching?", in o'KEEFFE Anne \& MCCARTHY Michael, (Eds.), The Routledge Handbook of Corpus Linguistics, London \& New York: Routledge, 359-370.

HOLME Randal, 2004, Mind, Metaphor and Language Teaching, Basingstoke: Palgrave MacMillan. JÓDAR-SÁNCHEZ José Antonio, 2019, "FrameNet as a resource to teach Spanish as a foreign language", in CARRIÓ-PASTOR María Luisa (Ed.), Teaching Language and Teaching Literature in Virtual Environments, Singapore: Springer, 121-149.

L'Hoмme Marie-Claude, 2020, Lexical Semantics for Terminology: An Introduction, Amsterdam: John Benjamins.

LAKOFF George \& JOHNSON Mark, 1980, Metaphors We Live By, Chicago \& London: The University of Chicago Press.

LEOW Ronald \& ZAMORA Celia, 2017, "Intentional and incidental L2 learning", in LOEWEN Shawn \& SATO Masatoshi (Eds.), The Routledge Handbook of Instructed Second Language Acquisition, Abingdon, Oxon: Routledge, 33-48.

LITTLEMORE Jeannette, 2009, Applying Cognitive Linguistics to Second Language Learning and Teaching, Basingstoke: Palgrave MacMillan.

LITTLEMORE Jeannette \& JUCHEM-GRUNDMANN Constanze, 2010, Applied Cognitive Linguistics in Second Language Learning and Teaching, [Special Issue], AILA Review 23.

LITTLEMORE Jeannette, KRENNMAYR Tina, TURNER James \& TURNER Sarah, 2014, “An investigation into metaphor use at different levels of second language writing”, Applied Linguistics 35(2), 117-144. LITTLEMORE Jeannette \& LOW Graham, 2006, Figurative Thinking and Foreign Language Learning, Basingstoke: Palgrave MacMillan.

LOW Graham, 2019, “Taking stock after three decades: 'On teaching metaphor' revisited”, in PIQUER-PÍRIZ Ana María \& ALEJO-GONZÁLEZ Rafael (Eds.), Metaphor in Foreign Language Instruction, Berlin \& Boston: De Gruyter Mouton, 37-55.

MACARTHUR Fiona, 2016, "Using metaphor in the teaching of second/foreign languages", in SEMINO Elena \& DEMJÉN Zsófia (Eds.), The Routledge Handbook of Metaphor and Language, Abingdon, Oxon: Routledge, 413-425.

NATION, Paul, 2013, Learning Vocabulary in Another Language, Cambridge: Cambridge University Press.

NUNAN David, 2004, Task-Based Language Teaching, Cambridge: Cambridge University Press. PETRUCK Miriam, 1996, "Frame Semantics”, in VERSCHUEREN Jef, öSTMAN Jan-Ola, BLOMMAERT Jan \& BULCAEN Chris, (Eds.), Handbook of Pragmatics, Amsterdam: John Benjamins, 1-13.

PITZL Marie-Luise, 2018, Creativity in English as a Lingua Franca: Idiom and Metaphor, Berlin \& Boston: De Gruyter Mouton.

RUPPENHOFER Josef, ELlSWORTH Michael, PETRUCK Miriam, JOHNSON Christopher \& SCHEFFCZYK Jan, 2016, FrameNet II: Extended Theory and Practice. Available at https://framenet2.icsi.berkeley.edu/ docs/r1.7/book.pdf SPENCER David, 2016, Gateway B2: Student's Book, $2^{\text {nd }}$ Edition, London: Macmillan Education. SULLIVAN Karen, 2016, "Integrating constructional semantics and conceptual metaphor", Constructions and Frames 8(2), 141-165. 
WILLIS Dave \& WILLIS Jane, 2007, Doing Task-based Teaching, Oxford: Oxford University Press.

WILLIS Jane, 1996a, A framework for task-based learning, Harlow: Longman Addison-Wesley.

WILLIS Jane, 1996b, “A flexible framework for task-based learning”, in wiLLIS Jane \& WILLIS Dave

(Eds.), Challenge and Change in Language Teaching, Oxford: Heinemann, 52-62.

XU Fang \& LI Tao, 2011, "Semantic frame and EVT for Chinese EFL learners", Journal of Language

Teaching and Research 2(3), 649-654.

\section{APPENDIXES}

I. Sample teaching unit on discussing life stories

Topic: Life stories

EFL Level: B2 (CEFR)

Target group: older teenagers/ university students

Main objectives:

- students will be able to report life stories

- students will become aware of the use of metaphor in describing life events

Method: Semantic frame-inspired TBLT

Materials: PC, Internet, texts, FrameNet

Skills involved: speaking, listening, reading, writing

Link to EFL textbook: Follow up to Gateway B2, $2^{\text {nd }}$ edition, Macmillan (Unit 4 "Extraordinary talents")

\section{A) Pre-task}

"Life is a journey" is one of the most famous phrases that we hear in our life. Have a look at a website with quotes about "life is a journey": inspirational-quotes-life-journey-treasure/amp. Do you also think of your experiences as being different parts of a journey?

Consider Paulo Coelho's quotation: “It's one thing to feel that you are on the right path, but it's another to think that yours is the only path

What do you think the topic of this lesson is? 
B) Task cycle

1. Task

Form groups of four and read your task.

Your school wants to put on a show at the end of the term. The show is called "The incredible life journey of a famous person". Your task is information about his/her life and present it to the class.

Each group should choose a famous person and search information on the Internet about him/her. Decide which types of information (pers different members of your group should look for. Take notes using the fact file below.

Full name

Place of birth

Childhood

Difficulties

Achievements

Extraordinary talent/ aptitudes/ features

2. Planning

Work together to organize the information you have collected and prepare your presentation about the famous person that your group has

3. Report

Choose a member of your group to present your work.

Decide which group has presented the most interesting life story. Vote: Who will be the famous person of the show?

\section{c) Language focus}

1. Analysis

When we talk about our life, we often use words that have a connection with motion: our life events are like different parts of a journey. This i metaphorically.

Read the text ${ }^{13}$ about Coelho's life and answer the following questions. ${ }^{14}$

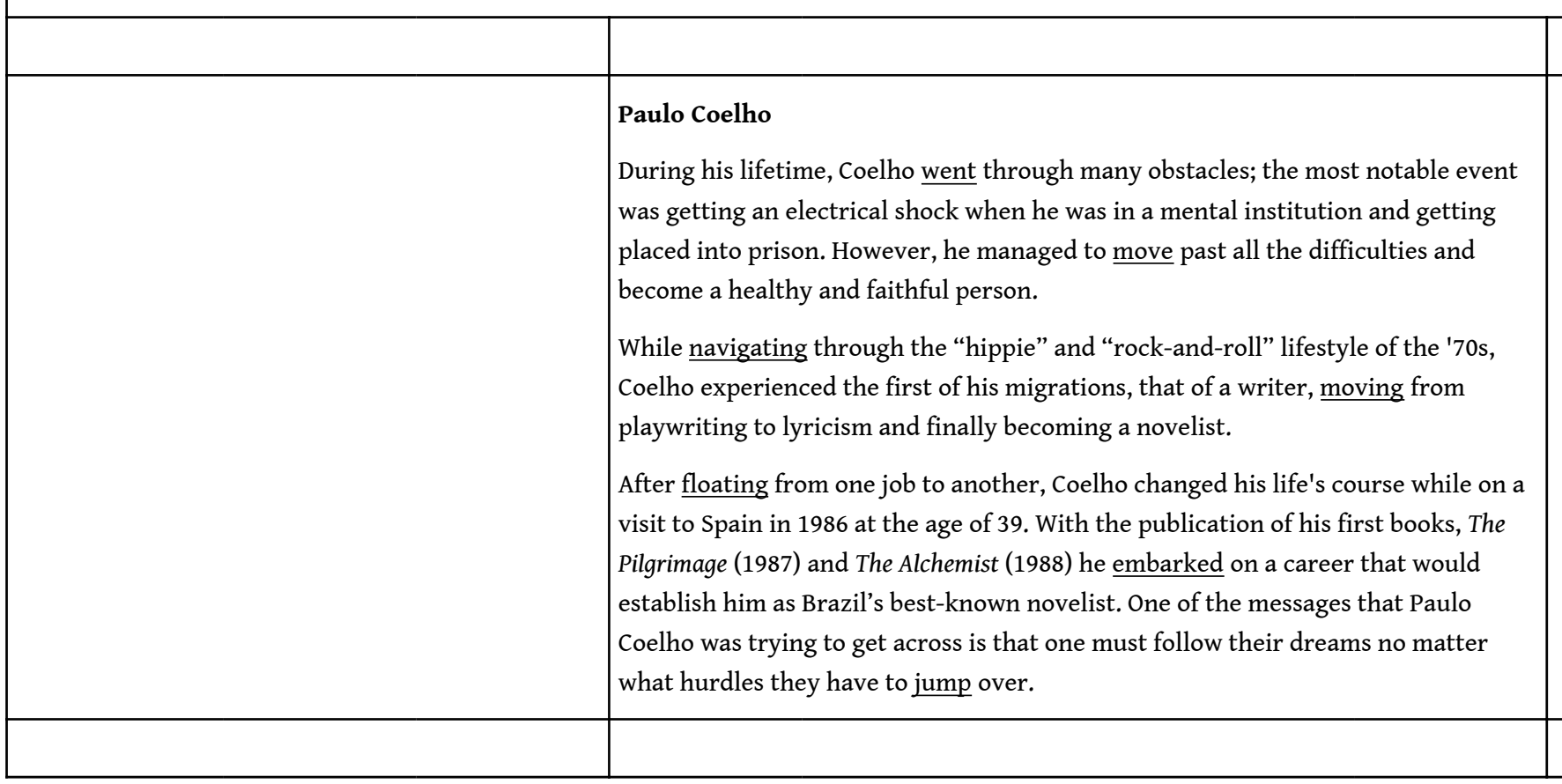


a) What do the underlined words have in common?

b) Underline the prepositions that follow the underlined words. Which of the following ideas do they express?

source:

goal:

path:

Read the meaning of SOURCE, PATH, GOAL, and examples in FrameNet (https://framenet2.icsi.berkeley.edu/fnReports/data/frame/Motion.xm

c) Find nouns in the text that have a connection with motion and are used to refer to

changes in life:

difficulties in life:

\section{Practice}

Activity 1 (controlled)

Read the text ${ }^{15}$ about Rowling's life and complete the gaps with words that have a connection with motion and journeys. Use words from the

Verbs: go get pass reach climb propel launch

Nouns: direction step journey pathway drive

\section{J.K. Rowling}

Much like the main character in her Harry Potter fantasy series of books, J.K. Rowling (1) pathway to success. Within five years, she quickly became one of the richest wome Britain. But there have been many events in Joanne Rowling's life that have contribut from rags to riches.

Rowling's humble beginnings can be traced back seven years after graduating from $u$ is the time when she saw herself as a failure. Her mother had (3) away, she h marriage, she had no permanent work, and she had a young daughter to take care of. seemingly hopeless situation was the same source of inspiration that (4) Row becoming a huge success. How did this single mother (5) out of poverty and $f$ become world's richest author? With relentless persistence and sheer hard work! Wri way for Rowling to cope with her depression. She (6) a turning point in her st depression only after the vision of her Harry Potter storyline became clearer.

The Harry Potter series became a bestseller all over the world, and it was adapted int successful film series that (7) ________- the careers of many young actors. That amount and obviously, millions of dollars into Rowling's pocket- would be enough to send $\mathrm{m}$ wrong (8) _-__-__._. At the very least, most people would retire and live a life of luxury didn't stop. Despite achieving the highest acclaim one can possibly achieve in her fie on writing. Rowling possessed a fierce determination to (10) where sl continuing to work diligently toward new goals.

Hopefully the zero to hero story of J.K. Rowling will encourage you to never give up o dreams. Doing what you really like is one of the most important first (11) tow your goals. Whether it be on writing or in any other fields, keeping the passion alive enough fuel to continue the (12) 




\section{PATH}

e.g. During his lifetime, he went through many obstacles.

SOURCE

e.g. She climbed out of poverty and failure.

\section{GOAL}

e.g. She reached a turning poin in her struggle with depression

Activity 3 (free, communicative)

Speaking:

Tell your partner about a person who is important to you. Describe this person's life: major events, difficulties, accomplishments. 
Topic: Health problems

EFL Level: B2 (CEFR)

Target group: older teenagers/ university students

\section{Main objectives:}

- students will be able to discuss experiences of health problems

- students will become aware of the use of metaphor in describing experiences of health problems

Method: Semantic frame-inspired TBLT

Materials: PC, Internet, texts, MetaNet

Skills involved: speaking, listening, reading, writing

Link to EFL textbook: Follow up to Gateway B2, 2nd edition, Macmillan (Unit 8 "Surviving disaster")

\section{A) Pre-task}

Watch the video titled "I Am Wuhan: Let's fight side by side until we win" (3:10 minutes) at https://www.youtube.com/watch?v=s5t8pYYLD When you are ill and you are trying to stay healthy, do you think of yourself as fighting a battle? Who is the enemy?

What do you think the topic of this lesson is?

B) Task cycle

1. Task

Form groups of four and read your task.

Your school will participate in a project called "The World's Greatest Problems in the 21st Century" and has decided to make a leaflet with task is to collect information about how the world has fought against this deadly disease and present it to the class.

Decide which types of information about the COVID-19 pandemic the different members of your group should look for. You can consider di politicians') about the country assigned to your group and collect information, pictures and visuals.

\section{Planning}

Organize the information you have collected to prepare your presentation.

3. Report

Choose a member of your group to present your work.

Decide what to include in the leaflet.

C) Language focus

1. Analysis

When we talk about a disease, we often use words that have a connection with war. This is an example of thinking and speaking metaphoric Read the text ${ }^{18}$ from the video "I Am Wuhan: Let's fight side by side until we win" and answer the following questions. ${ }^{19}$ 


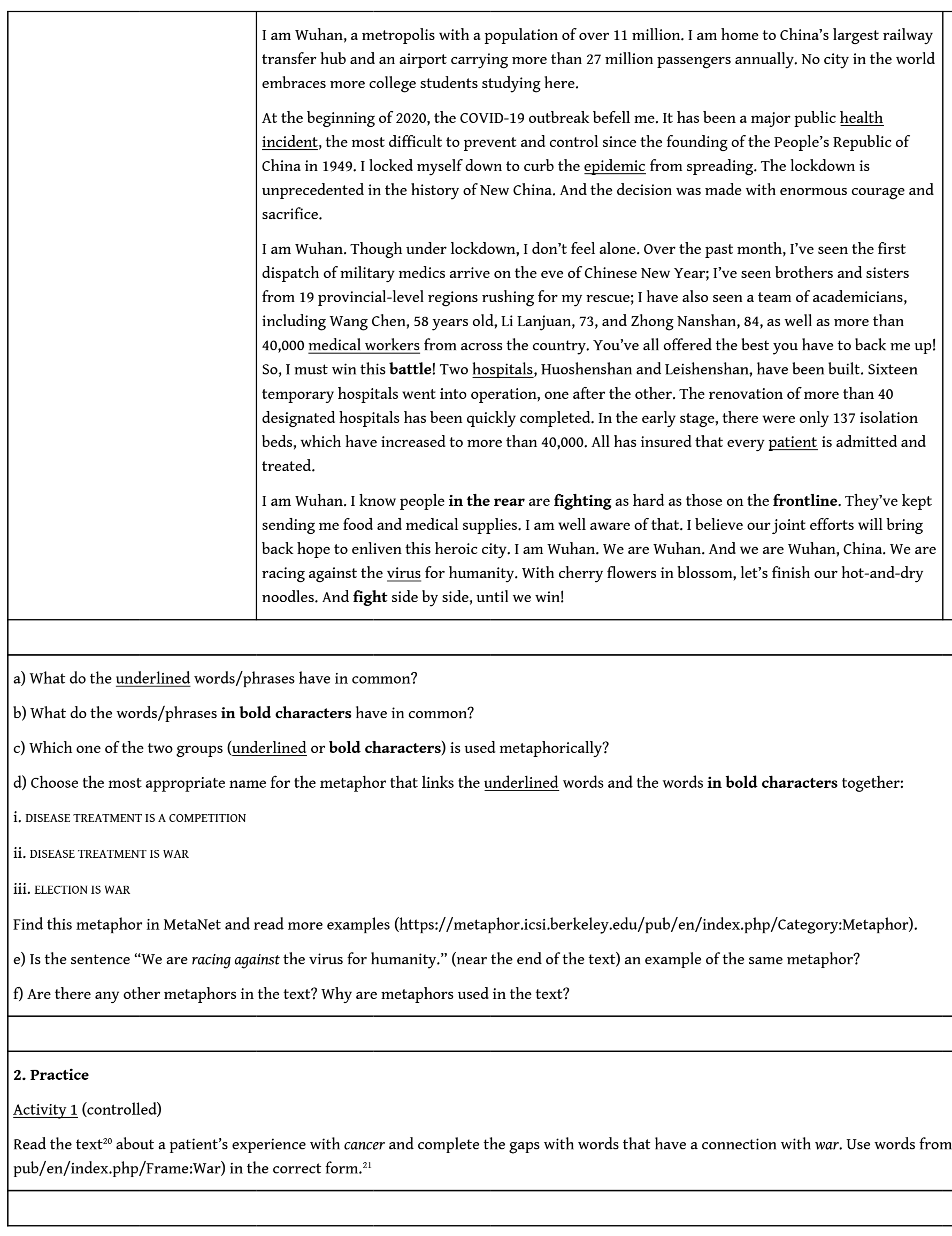




\begin{tabular}{|c|c|}
\hline & 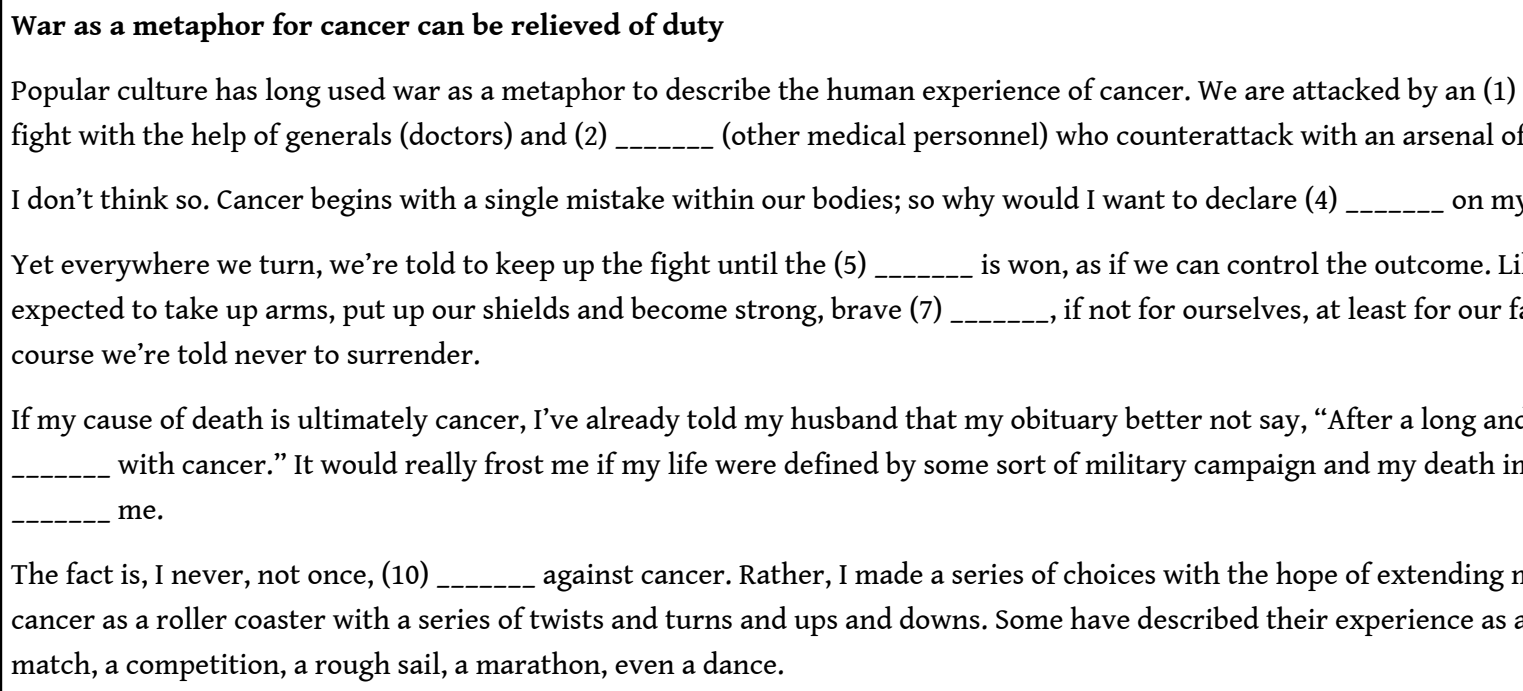 \\
\hline \multicolumn{2}{|l|}{ Activity 2 (guided) } \\
\hline \multicolumn{2}{|l|}{ Writing: } \\
\hline \multicolumn{2}{|c|}{ Work in pairs and write a hopeful quote to inspire people who experience a chronic disease (such as cancer, heart disease, diabetes, arthriti } \\
\hline \multicolumn{2}{|c|}{$\begin{array}{l}\text { Have a quick look at a website with hopeful quotes: https://www.rogelcancercenter.org/living-with-cancer/sharing-hope/hopeful-quotes. } \\
\text { metaphorical language used. }\end{array}$} \\
\hline \multicolumn{2}{|c|}{$\begin{array}{l}\text { Decide on the metaphor you will use. To get some ideas, read the last paragraph of the previous text once again. Tip: you can find words/ph } \\
\text { you write your hopeful quote in MetaNet (https://metaphor.icsi.berkeley.edu/pub/en/index.php/Category:Frame). }\end{array}$} \\
\hline \multicolumn{2}{|c|}{ Activity 3 (free, communicative) } \\
\hline \multicolumn{2}{|l|}{ Speaking: } \\
\hline
\end{tabular}

\section{NOTES}

1. There are constructs similar to frames, including cognitive domains, idealized cognitive models, and mental spaces, which are used in other CL frameworks to refer to "structured encyclopedic knowledge" [Cienki 2007].

2. This means that each sense of a polysemous word, i.e. each LU, should be considered against different background knowledge.

3. https://framenet.icsi.berkeley.edu/fndrupal

4. FrameNet uses font and colour differences for the names of frames and FEs. Here we use small capitals for the names of FEs and square brackets for frames.

5. The technicalities of the annotation layers are not discussed here because they are not used in the proposed lesson plans. However, to briefly illustrate how FrameNet links FEs to their syntactic realizations in order specify the constituents with which words combine in both semantic and syntactic terms, we can consider the following example of jump (v) as annotation target and the corresponding valence pattern.

\section{One morning in mid-January II JUMPED over the railings and climbed up to the parapet of the gate .}




\begin{tabular}{||l||l|l|l|}
\hline \hline Path & Self mover & Time & Time \\
\hline PP[over] & NP & NP & PP[in] \\
Dep & Ext & Dep & Dep \\
\hline
\end{tabular}

6. https://metanet.icsi.berkeley.edu/metanet

7. This rationale is in line with Sullivan's [2016: 142] call for integrating CL theories to "capture metaphoric language in its linguistic and conceptual entirety". For example, conceptual metaphor theory captures only the conceptual structure of metaphors, while frame semantics can also account for the way words and phrases evoke the source and target domains of metaphor.

8. For an overview of the similarities and differences between different versions of TBLT see Ellis [2017], who distinguishes "task-based" from merely "task-supported" language teaching [2017: 111], but also highlights that "TBLT does not prescribe a narrow set of techniques and does not constitute a totally uniform way of teaching" [2017: 114]. In this paper we employ Willis's [1996a] task-based learning framework.

9. As Leow \& Zamora [2017: 40] point out, there is "some conflation between incidental learning (typically associated with 'picking up' a language and opposed to intentional learning) and implicit learning (typically associated with a lack of awareness and opposed to explicit learning)". In the TBLT framework discussed here learners' attention is intentionally/ explicitly drawn to specific L2 forms during the language focus phase after they have been involved in incidental/ implicit learning during the task cycle while working to achieve a communicative goal.

10. A parallel can be drawn here with data-driven learning (for a description of the cline from teacher-led to learner-led DDL activities see Gilquin \& Granger [2010:362-365]) and for a brief overview of deductive and inductive approaches to L2 corpus use see Dolgova \& Tyler [2019: 954-955]).

11. For a discussion of the value of learners' metaphorical creativity as evidenced in an English as a Lingua Franca corpus, see Pitzl [2018].

12. Alternatively, an evaluation questionnaire could be filled at the end of the lesson.

13. The text is based on https://www.bartleby.com/essay/The-Life-of-Paulo-CoelhoFKD7CN4JDB6S and https://www.biography.com/writer/paulo-coelho .

14. Key: a) verbs of motion, b) SOURCE: from; GOAL: to, on; PATH: through, past, over, c) changes in life: migrations, life's course; difficulties in life: hurdles

15. The text is based on https://fullylived.com/j-k-rowlings-zero-to-hero-story and https:// www.grunge.com/86112/how-jk-rowling-welfare-wizarding-wonder .

16. Key: 1. pathway, 2. journey, 3. passed, 4. propelled, 5. climb, 6. reached, 7. launched, 8. direction, 9. went, 10. get, 11. steps, 12. drive

17. To check their sentences grammatically, students can be guided to use FrameNet's "annotation" reports or a monolingual learners' dictionary (e.g. http:// www.macmillandictionary.com).

18. According to the Text Analyzer (http://www.roadtogrammar.com/textanalysis), the text corresponds to B2 (CEFR); no changes have been made in the original text.

19. Key: a) disease, b) war, c) yellow - ii, d) DISEASE TREATMENT IS A COMPETITION, e) personification (CITY IS A PERSON).

20. The text has been adapted from https://www.rogelcancercenter.org/living-with-cancer/ sharing-hope/war-metaphor-cancer-can-be-relieved-duty .

21. Key: 1. enemy, 2. allies, 3. weapons, 4. war, 5. victory, 6. soldiers, 7. warriors, 8. battle, 9. conquered, 10. battled 


\section{ABSTRACTS}

The paper aims to make a contribution to recent discussions of the application of a particular cognitive linguistic theory, frame semantics, to the field of language teaching. The proposal put forward demonstrates the meeting points between frame semantics and task-based language teaching. In explaining why and how frame semantics can be integrated with task-based language teaching, we point out the key role of contextualization (both situational and linguistic). The implementation of the proposed integration is illustrated in the context of metaphor teaching: we present sample teaching units which raise English as a Foreign Language learners' awareness of metaphor. These examples show how frame semantics can find its way into the task-based framework with a view to enhancing vocabulary acquisition through the conceptual and contextual grouping of lexico-grammatical items.

L'article a pour objectif d'apporter une contribution aux discussions récentes sur l'application d'une théorie de linguistique cognitive particulière dans le domaine de l'enseignement des langues, la sémantique des cadres. Notre proposition démontre les points de rencontre entre la sémantique des cadres et l'enseignement des langues dans une approche actionnelle. En expliquant pourquoi et comment la sémantique des cadres peut être intégrée à l'approche actionnelle, nous soulignons le rôle clé de la contextualisation, à la fois situationnelle et linguistique. La mise en œuvre de l'intégration proposée est illustrée dans le contexte de l'enseignement d'éléments de langage métaphorique: nous présentons des exemples d'unités d'enseignement qui sensibilisent les apprenants d'anglais langue seconde à la métaphore. Ces exemples montrent comment la sémantique des cadres peut trouver sa place dans le contexte d'une approche actionnelle en vue d'améliorer l'acquisition du vocabulaire à travers le regroupement conceptuel et contextuel d'éléments lexico-grammaticaux.

\section{INDEX}

Mots-clés: sémantique des cadres, FrameNet, MetaNet, approche actionnelle, métaphore

Keywords: frame semantics, FrameNet, MetaNet, task-based language teaching, metaphor

\section{AUTHOR}

\section{THOMAI DALPANAGIOTI}

Aristotle University of Thessaloniki, Greece

thomdalp@enl.auth.gr 